Tema: Tecnologias e Inovações Aplicadas a Suplly

\title{
SIMULAÇÃO MATEMÁTICA APLICADA AO PROCESSO DE ABASTECIMENTO DE METÁLICOS NA ACIARIA DE AÇOS LONGOS DA CSN*
}

\author{
Ubaldo Marques Silva Filho ${ }^{1}$ \\ Amaury Vieira de Oliveira ${ }^{2}$ \\ Luigi Guarino Neto ${ }^{3}$ \\ Eduardo Vinícius dos Santos ${ }^{4}$
}

\begin{abstract}
Resumo
Dentro da estratégia de investimentos da CSN para a Usina Presidente Vargas UPV - a construção de uma unidade produtiva de aços longos com capacidade de 500 mil toneladas/ano está em processo de conclusão. Entre os vários processos existentes na unidade, a logística interna de movimentação de metálicos (sucata e gusa sólido) e o abastecimento da Aciaria Elétrica com cestões, são processos que se não estiverem bem configurados podem restringir as capacidades produtivas almejadas, comprometendo o alcance das metas estratégicas. Para analisar os possíveis impactos e restrições a produção, foi desenvolvido um modelo matemático em computador para simular as operações virtualmente, como forma de determinar as melhores condições operacionais e prever quaisquer gargalos no sistema.
\end{abstract}

Palavras-chave: Logística interna; Ferrovia; Aços longos, Simulação em computador; Modelagem matemática; Eventos discretos.

\section{MATHEMATICAL SIMULATION APPLIED TO THE METAL SUPPLY PROCESS IN STEELMAKING LONG STEEL CSN}

\begin{abstract}
Within the investment strategy of CSN to the Presidente Vargas Steelworks - UPV, the construction of a long steel unit with capacity of $500 \mathrm{Kt} /$ year is in process of completion. Among the various existing processes in the unit, the internal logistics of moving metal (scrap and solid pig) and supply of Electric Steelmaking are processes that if are not well configured can restrict the desired productive capacity and compromise the achievement of strategic goals. To analyze the potential impacts and production constraints, a mathematical computer model to simulate the virtually operations and determine the best operating conditions and predict any bottlenecks in the system was developed.
\end{abstract}

Keywords: Internal logistics; Railway; Long steel; Computer simulation; Mathematical Modeling; Discrete events.

1 Administrador de Empresas, Gerente de Logística, CSN, São Paulo, SP, Brasil.

2 Matemático, MBA em Gestão Empresarial FGV, Especialista em Metálicos, CSN, Volta Redonda, $R J$, Brasil.

Engenheiro Civil, Especialista em Logística, CSN, São Paulo, SP, Brasil.

4 Engenheiro de Produção, Coordenador de Logística, CSN, Volta Redonda, RJ, Brasil.

\footnotetext{
* Contribuição técnica ao 33० Seminário de Logística - Suprimentos, PCP, Transportes, 13 a 16 de maio de 2014, São Paulo, SP, Brasil.
} 


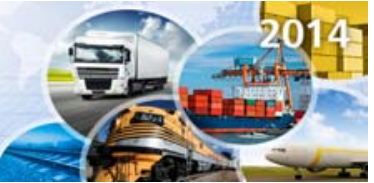

\section{INTRODUÇÃO}

A CSN é atualmente a maior usina integrada da América Latina. Foi privatizada em 1993 e após uma reestruturação se tornou umas das empresas mais competitivas do setor em todo mundo. Atua em cinco pilares de negócios sendo siderurgia, mineração, logística, energia e cimentos.

Dentro da estratégia de investimentos da CSN para siderurgia, está em processo de finalização de construção uma unidade produtiva de aços longos, localizada na estrutura da Usina Presidente Vargas - UPV em Volta Redonda / RJ (Figura 1).

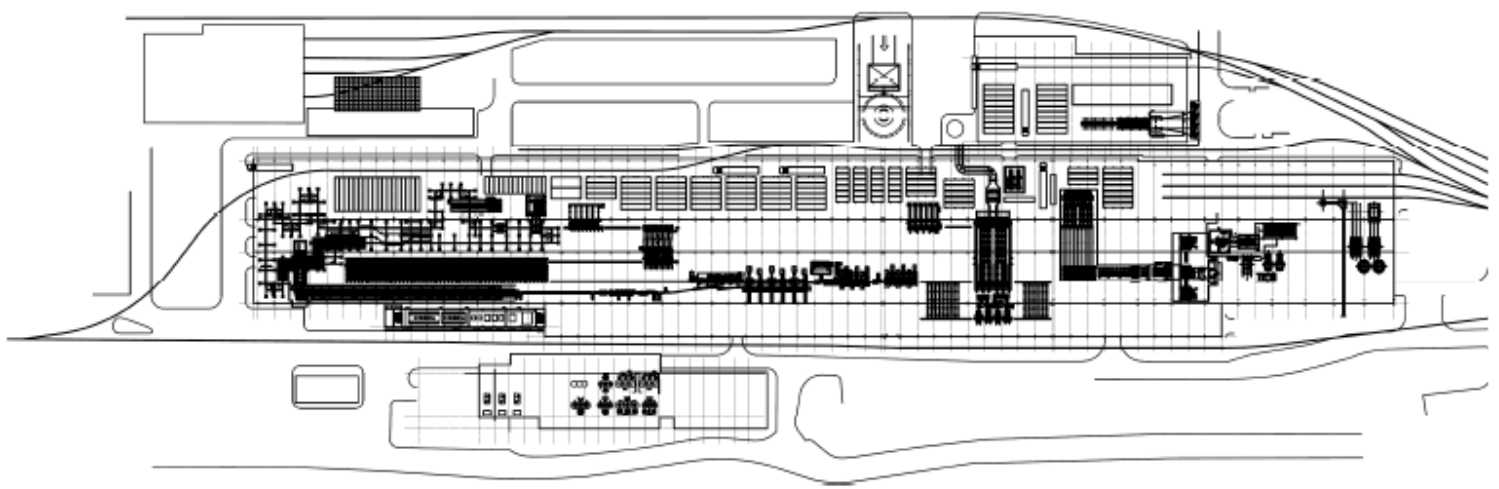

Figura 1. Visão Geral da Planta de Aços Longos da UPV.

A nova planta é uma usina semi-integrada. O aço é obtido a partir de ferro secundário (sucata de aço e gusa) não havendo a etapa de redução de minério de ferro, diferente de uma usina integrada onde o aço é obtido a partir do ferro primário (minério de ferro), que é transformado em ferro gusa nos alto-fornos pelo processo de redução (Figura 2 - Tabela 1 ) [1].

O processo tem início na aciaria, onde a sucata e o gusa são transformados novamente em aço comercial por meio de emprego de fornos elétricos de fusão. A capacidade produtiva da unidade é de 500 Mil toneladas / ano (considerando todos os processos produtivos).

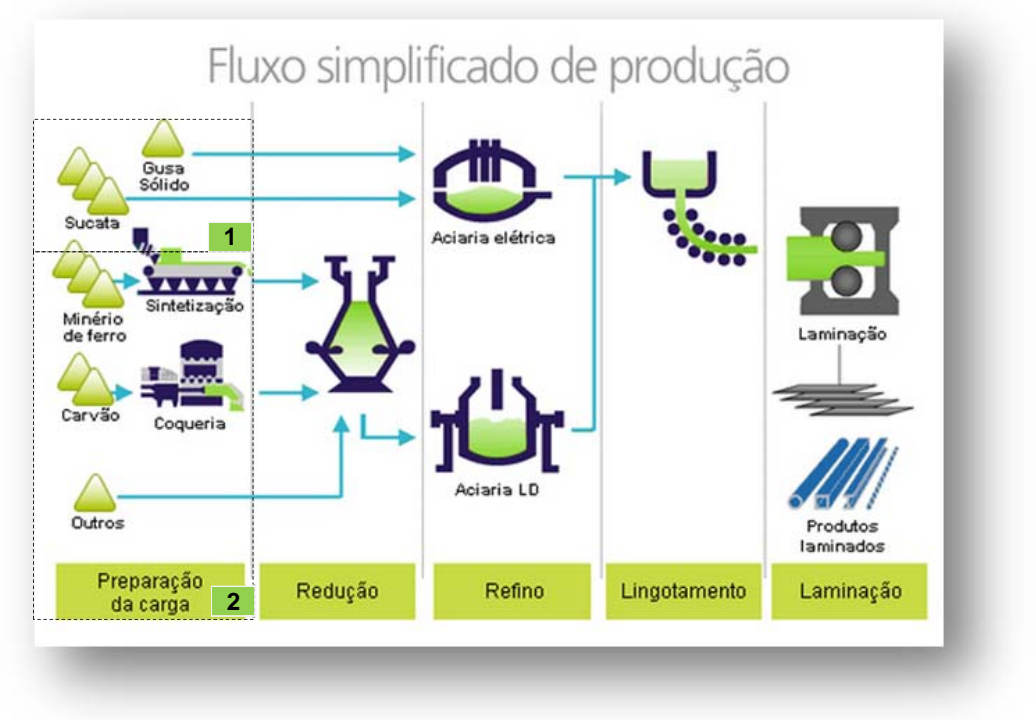

Figura 2. Visão Geral do processo de produção.

\footnotetext{
* Contribuição técnica ao $33^{\circ}$ Seminário de Logística - Suprimentos, PCP, Transportes, 13 a 16 de maio de 2014, São Paulo, SP, Brasil.
} 


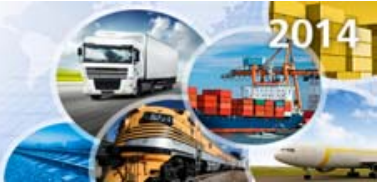

Tabela 1. Tipos de Usinas Siderúrgicas

\begin{tabular}{|cc|}
\hline 1 - Semi-integradas & $\mathbf{2}$ - Integradas \\
\hline $\begin{array}{c}\text { Operam duas fases: refino e laminação. } \\
\text { Estas usinas partem de ferro gusa ou sucata } \\
\text { metálica adquirida de terceiros para } \\
\text { transformá-los em aço em aciarias elétricas e } \\
\text { sua posterior laminação. }\end{array}$ & $\begin{array}{c}\text { Operam as três fases básicas: redução, } \\
\text { refino e laminação; Participam de todo o } \\
\text { processo produtivo do aço. }\end{array}$ \\
\hline
\end{tabular}

Entre os vários processos existentes na unidade de Aços Longos da UPV, a logística interna de movimentação de metálicos (sucata e gusa sólido) e o abastecimento da Aciaria Elétrica com cestões para o Forno Elétrico a Arco, poderão restringir as capacidades produtivas almejadas, caso estas não estejam bem configuradas, tornando-se gargalos para o alcance das metas de produção.

Diante da complexidade dessa questão, a qual envolve investimentos significativos e pode afetar a produção de aço, a simulação em computador foi adotada como ferramenta capaz de garantir uma resposta confiável quanto aos possíveis problemas apresentados e possíveis soluções em caso do não atendimento previsto em projeto.

Este trabalho analisará previamente as operações através de simulação matemática de eventos discretos, para encontrar pontos críticos no processo e propor soluções como forma de maximizar as operações de movimentação e abastecimento de metálicos dos cestões do Forno Elétrico a Arco.

\subsection{Logística de Abastecimento dos Insumos Metálicos}

A planta de Aços longos está localizada dentro da Usina Presidente Vargas em Volta Redonda / RJ próximo a saída Leste, com operações integradas as da Usina de Aços Planos (Figura 3).

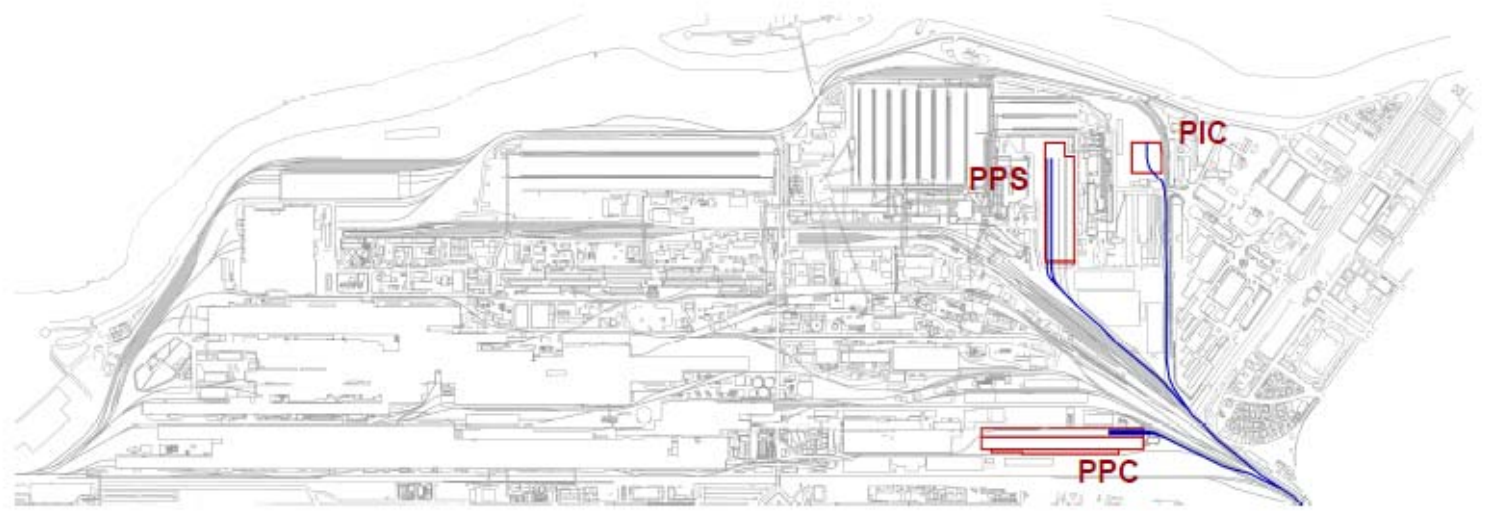

Figura 3. Localização dos Pátios Internos.

Os principais insumos da planta, sucata metálica e ferro gusa, são recebidos pelo modal ferroviário e rodoviário. A descarga é realizada no PPS - Pátio de Preparação de Sucatas (Sucatas) e no PIC - Pátio interno de Cambagem (Gusa).

Estes materiais são transferidos para o pátio interno de preparação de cestões localizado no interior da área fabril, via ferrovia, conforme programação da produção. O abastecimento de metálicos dos cestões do forno elétrico serão realizados

\footnotetext{
* Contribuição técnica ao 33० Seminário de Logística - Suprimentos, PCP, Transportes, 13 a 16 de maio de 2014, São Paulo, SP, Brasil.
} 
diretamente dos vagões, que servem como "estoque sobre rodas" e que depois de esvaziados retornam aos pátios primários para novos carregamentos.

Em usinas de Aços Longos similares, o estoque dos metálicos são armazenados em baias próximas ao carregamento dos cestões. No projeto da CSN devido a restrição de espaço adotou-se manter os estoques do PPC distribuídos em 21 vagões separados em três linhas férreas (Figura 4).

Estarão disponíveis no processo mais 19 vagões carregados para reabastecimento dos estoques quando necessário. Estima-se que a manobra da composição desde o pátio de preparação de sucata até o pátio de carregamento dos cestões tenha uma duração de 40 minutos.

Os metálicos são movimentados por duas pontes rolantes com eletroímãs que levarão o material de cada vagão até os dois cestões conforme o mix de produção desejado.

O abastecimento de cada cestão obedece a uma receita específica que leva em consideração questões operacionais como: (a) o tipo de aço a ser produzido, (b) os diferentes tipos de sucatas disponíveis e (c) o percentual de gusa adicionado que podem influenciar no processo de fusão do forno. Essa receita pode ser alterada conforme os custos da matéria prima apurados, possibilitando um menor custo produtivo.

Os estoques precisam estar dispostos nos vagões de maneira que estejam disponíveis para compor a receita de carregamento programada pela produção.

O planejamento correto da distribuição dos tipos de metálicos nos vagões é extremamente importante já que minimizará as movimentações ferroviárias para reabastecimento dos estoques e otimizará a movimentação das pontes rolantes, garantindo o cumprimento das metas de produção.

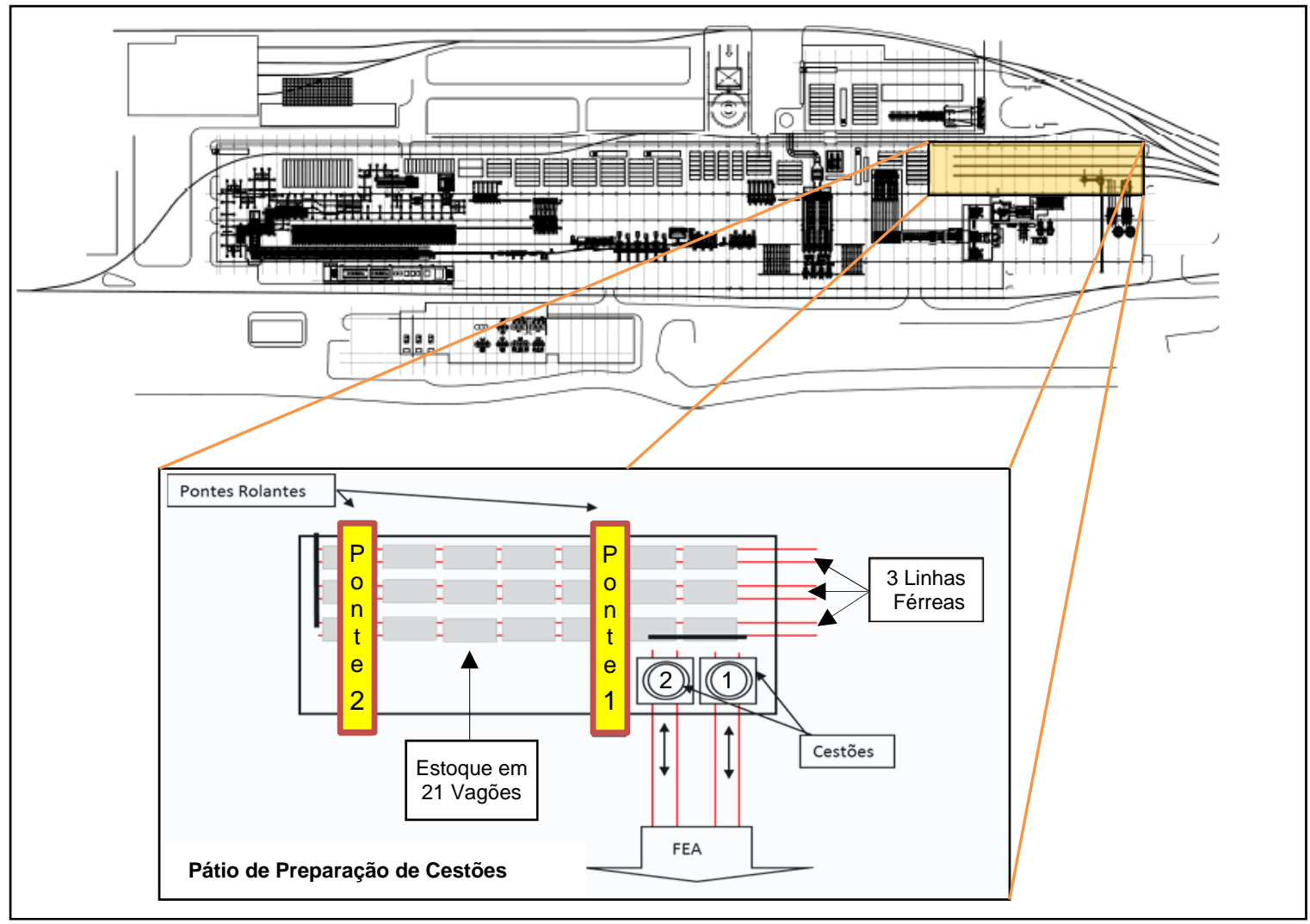

Figura 4. Layout do estoque de Metálicos.

\footnotetext{
* Contribuição técnica ao $33^{\circ}$ Seminário de Logística - Suprimentos, PCP, Transportes, 13 a 16 de maio de 2014, São Paulo, SP, Brasil.
} 
Cada corrida da aciaria é composta por dois cestões, o primeiro com 36 toneladas e o segundo com 20 toneladas de matéria prima (peso médio de referência). Os cestões são carregados em camadas de metálicos de densidades específicas. Após a carga da segunda camada, cada cestão recebe uma carga de Cal, dando continuidade no processo até sua carga completa. Após a carga completa, eles são transferidos para Aciaria Elétrica para abastecimento do forno e início do processo de fusão. Os cestões vazios retornam para o pátio de preparação para serem carregados em nova corrida (Figura 5).

Estima-se que cada corrida tenha um tempo de ciclo de 52 minutos, calculado para executar sequencialmente o fluxo do processo na Figura 5.

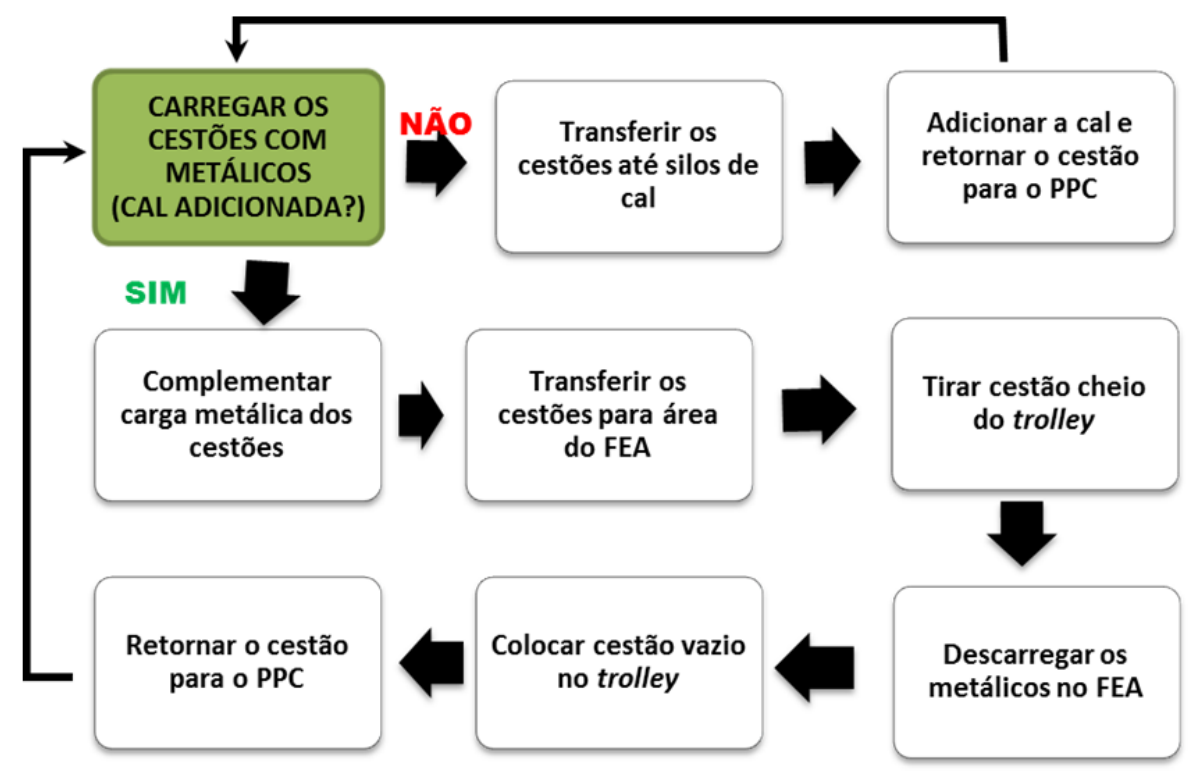

Figura 5. Processo de carregamento dos cestões.

\section{MATERIAIS E MÉTODOS}

Diante da complexidade apresentada e o risco de poder afetar a produção de Aço, a simulação em computador foi adotada enquanto ferramenta capaz de garantir uma resposta confiável quanto aos possíveis problemas de produtividade.

Como objetivos específicos da simulação matemática estão:

- Determinar a melhor disposição dos vagões no Pátio de Preparação de Sucatas PPC para atender as programações de produção;

- Determinar as manobras ferroviárias necessárias ao processo;

- Avaliar os recursos e capacidades operacionais, levantando suas restrições e gargalos, e

- Propor melhorias ao processo.

\subsection{Simulação em Computador}

A simulação computacional é uma técnica utilizada tanto para projeto e avaliação de novos sistemas, bem como para reconfiguração física ou mudanças no controle e regras de operação de sistemas existentes.

As suas aplicações têm crescido em todas as áreas, auxiliando os gestores na tomada de decisão em problemas complexos e dinâmicos, possibilitando um melhor conhecimento dos processos nas organizações.

\footnotetext{
* Contribuição técnica ao $33^{\circ}$ Seminário de Logística - Suprimentos, PCP, Transportes, 13 a 16 de maio de 2014, São Paulo, SP, Brasil.
} 
A simulação computacional tem como objetivo principal representar logicamente um sistema real, suas estruturas físicas, a dinâmica dos negócios, as interações entre os processos e demonstrar qual será o comportamento futuro frente aos cenários propostos.

\subsection{Desenvolvimento do Modelo Matemático}

\subsubsection{Metodologia utilizada}

Encontramos na literatura especializada as metodologias necessárias para desenvolvimento de modelos de simulação (Figura 6). Basicamente o desenvolvimento é composto por três grandes etapas detalhadas abaixo:

- Concepção do modelo: Etapa onde os objetivos da simulação são detalhados, o escopo do trabalho é definido e os dados para simulação dos cenários são coletados. O produto final desta fase é um 'modelo conceitual', representado de acordo com alguma técnica de apresentação e validado por especialista do processo analisado.

- Implementação do modelo: Nesta fase o 'modelo conceitual', é convertido em um modelo computacional através da utilização de alguma linguagem de simulação ou software comercial. Os resultados desta implementação devem ser confrontados com o modelo conceitual para validar que o modelo é uma representação fiel da realidade.

- Análise dos resultados: Nesta fase, após o modelo validado, são gerados diversos cenários para avaliar o comportamento das operações. Os resultados são documentados para análise, sendo a base para geração de conclusões e recomendações sobre os sistemas estudados.

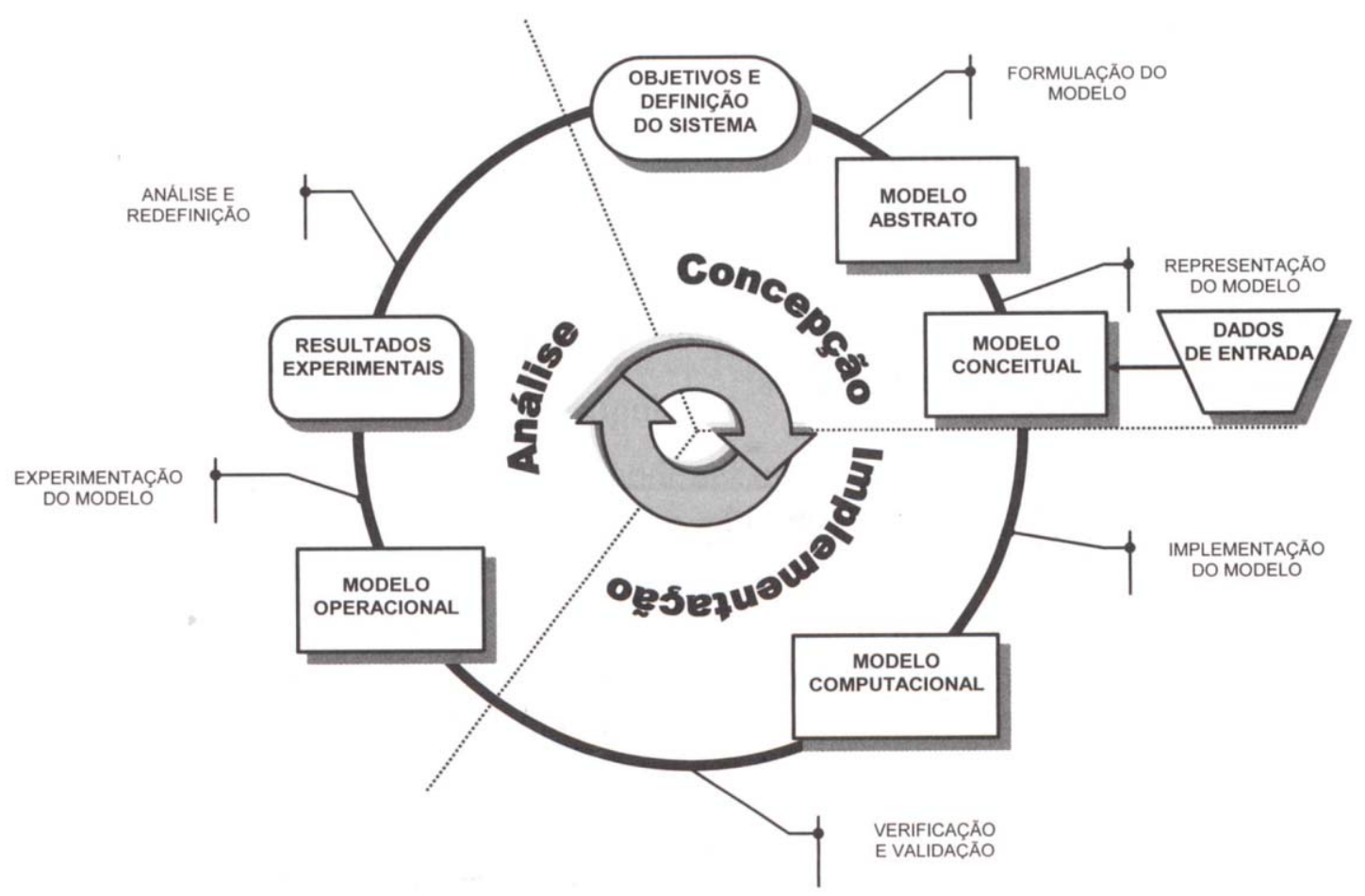

Figura 6. Metodologia de Simulação [2].

\footnotetext{
* Contribuição técnica ao $33^{\circ}$ Seminário de Logística - Suprimentos, PCP, Transportes, 13 a 16 de maio de 2014, São Paulo, SP, Brasil.
} 


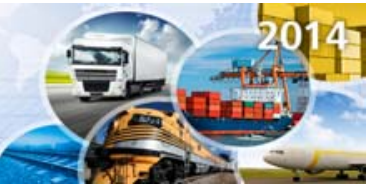

\subsubsection{Desenvolvimento prático do modelo}

Para este projeto, foi utilizado o software comercial de simulação Promodel, onde foram representadas com elevado grau de precisão as operações futuras do abastecimento dos cestões de Aços Longos e suas estruturas (Figura 7).

1) Forno Elétrico a Arco;

2) Cestões (2);

3) Vagões de Estoque de Metálicos;

4) Linhas Férreas;

5) Pontes rolantes (2).

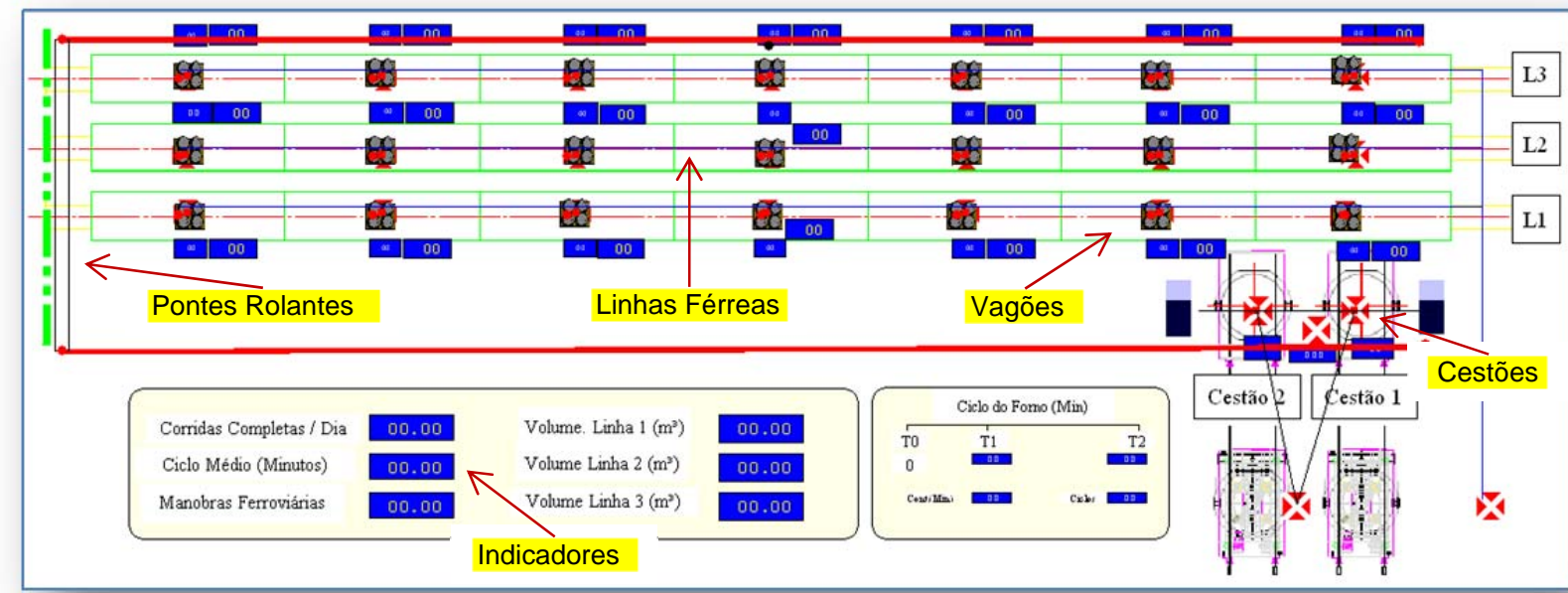

Figura 7. Modelo Matemático no Promodel.

Fluxos Mapeados no projeto:

- Manobra de composições para abastecimento e reabastecimento de metálicos nas linhas férreas;

- Carregamento dos cestões com as pontes rolantes;

- Carregamento de Cal nos cestões;

- Descarregamento dos cestões.

Indicadores gerados em tempo real:

- Total de corridas por dia;

- Tempo total por corrida;

- Quantidade de manobras ferroviárias;

- Estoque total de metálicos por linha.

Cockpit de Entrada de Dados:

A alimentação do modelo para simulação dos cenários é realizada através de um cockpit desenvolvido em software Excel, contemplando todas as informações necessárias para a geração dos cenários avaliados:

- Volume de matérias primas por tipo em cada vagão (Figura 8);

- Receita de montagem dos cestões (Figura 9);

- Velocidades / capacidade das pontes rolantes;

- Tempos / capacidade de cada processo ou recurso;

- Tipos de Sucatas utilizadas no processo (Figura 10).

\footnotetext{
* Contribuição técnica ao $33^{\circ}$ Seminário de Logística - Suprimentos, PCP, Transportes, 13 a 16 de maio de 2014, São Paulo, SP, Brasil.
} 


MIX DE METÁLlicos - TREM TIPO
\begin{tabular}{|l|c|c|c|c|c|c|c|c|}
\hline Input Manual - Posição & $\mathbf{7}$ & $\mathbf{6}$ & $\mathbf{5}$ & $\mathbf{4}$ & $\mathbf{3}$ & $\mathbf{2}$ & $\mathbf{1}$ \\
\hline Trem Tqpo & \multicolumn{7}{|c|}{ Material } \\
\hline Linha 3 & SH & SH & SH & TR & TR & TR & E1 \\
\hline Linha 2 & SH & SH & SH & TR & TR & E1 & E1 \\
\hline Linha 1 & SH & SH & TR & TR & E1 & E1 & E1 \\
\hline
\end{tabular}

Figura 8. Matéria prima por vagão.

\title{
운 $\overline{\mathrm{CSN}}$
}

\section{ENTRADA DE DADOS}

\begin{tabular}{|c|c|c|c|c|c|c|}
\hline \multicolumn{7}{|c|}{ ESTRATIFICAÇÃO OBJETIVADA ( ton ) } \\
\hline \multirow{2}{*}{ CAMADAS } & \multicolumn{2}{|c|}{20 CESTÃo } & \multirow[b]{2}{*}{ Ton Acum. } & \multicolumn{3}{|c|}{10 CESTÃo } \\
\hline & METÁLICOS & Ton & & METÁLICOS & Ton & Ton Acum. \\
\hline \multicolumn{7}{|l|}{$14 a$} \\
\hline \multicolumn{7}{|l|}{ 13a } \\
\hline \multicolumn{7}{|l|}{$12 a$} \\
\hline \multicolumn{7}{|l|}{$11 \mathrm{a}$} \\
\hline \multicolumn{7}{|l|}{$10 \mathrm{a}$} \\
\hline \multicolumn{7}{|l|}{$9 a$} \\
\hline \multicolumn{7}{|l|}{$8 a$} \\
\hline \multicolumn{7}{|l|}{$7 a$} \\
\hline \multirow{2}{*}{\multicolumn{7}{|c|}{$6 \mathbf{a}$}} \\
\hline \multicolumn{2}{|l|}{$5 a$} & & & & & \\
\hline $4 a$ & Shredder & 14 & 36 & Shredder & 7 & 20 \\
\hline $3 a$ & Tesourada & 14 & 22 & Tesourada & 6 & 13 \\
\hline $2 a$ & CAL & 2 & 8 & CAL & 1 & 7 \\
\hline $1 \mathrm{a}$ & Estamparia 1 & 6 & 6 & Estamparia 1 & 6 & 6 \\
\hline SOMA (t) & METÁLICOS & 36 & & & 20 & \\
\hline
\end{tabular}

Figura 9. Modelo de receita dos cestões.

\section{Tipos de Sucata utilizada na produção do Aço}

\author{
GS - Gusa Sólido \\ PI - Pesada de Indústria \\ RE - Recuperada \\ FO - FOFO \\ PP, PR, PM - Pacote de estamparia \\ preta, revestida e misto \\ MI - Mista
}

\section{SG - Sucata de Gusa \\ FR - Forjada}

EP, ER -Estamparia preta e revestida

SH - Shredded

$$
\text { CA - Cavaco }
$$

TR - Tesourada

Figura 10. Tipos de Sucata.

\subsubsection{Premissas adotadas}

Devido aos equipamentos não estarem instalados e não se conhecer precisamente sua produtividade foram utilizados como inputs iniciais para o simulador os valores de projeto, como por exemplo, os tempos de movimentação e capacidades dos eletroímãs das pontes rolantes para cada tipo de sucata.

Os tempos de manobras das composições foram estimados com base em movimentações semelhantes, podendo sofrer variações na operação real;

Foi utilizado para calculo de volume de sucata disponível nas linhas o vagão padrão gondola da ferrovia MRS Logística S/A.

\footnotetext{
* Contribuição técnica ao $33^{\circ}$ Seminário de Logística - Suprimentos, PCP, Transportes, 13 a 16 de maio de 2014, São Paulo, SP, Brasil.
} 


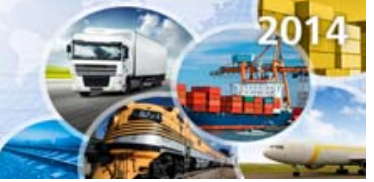

Somente a ponte rolante 1 tem acesso ao abastecimento do cestão 1 por definição do projeto. O cestão 2 pode ser abastecido pela ponte 1 e 2, porém não simultaneamente.

O volume máximo de movimentação por ponte é de $1 \mathrm{~m}^{3}$ de material metálico (capacidade do eletroímã).

Outras premissas foram adotadas para desenvolvimento do modelo e análise inicial. O modelo deverá ser 'refinado' assim que informações mais precisas estiverem disponíveis.

\section{RESULTADOS}

Com o modelo desenvolvido, validado e abastecido com as premissas acordadas com a equipe de produção, foram gerados cenários que trouxeram respostas às questões específicas esperadas do estudo.

\subsection{Determinar a Melhor Disposição dos Vagões no Pátio de Preparação de Sucatas PPC para Atender as Programações de Produção}

Em uma primeira rodada de simulações, a sucata disponível foi distribuída nos vagões seguindo o critério de manter a sucata menos densa mais próxima dos cestões, como forma de reduzir a movimentação das pontes rolantes (Figura 11).

\begin{tabular}{lccccccc}
\hline \multicolumn{7}{c}{ Distribuição da Sucata metálica nos Vagões } \\
\hline Linha 3 & SH & SH & SH & TR & TR & TR & E1 \\
Linha 2 & SH & SH & SH & TR & TR & E1 & E1 \\
Linha 1 & SH & SH & TR & TR & E1 & E1 & E1 \\
\hline
\end{tabular}

Legenda:

SH: Shredded;

TR: Tesourada;

E1: Estamparia;

Figura 11. Carregamento de Sucata nos Vagões.

Sendo assim, chegou-se em um modelo de trem tipo padronizado tanto para o estoque inicial quanto para o carregamento das composições de reposição (Figura 12).

\begin{tabular}{cccc}
\hline \multicolumn{3}{c}{ Modelo de Composição por linha } \\
\hline Linha 3 & 3 Vagões Shredded & $\begin{array}{c}3 \text { Vagões } \\
\text { Tesourada }\end{array}$ & 1 Vagão Estamparia \\
Linha 2 & 3 Vagões Shredded & $\begin{array}{c}\text { 2 Vagões } \\
\text { Tesourada }\end{array}$ & 2 Vagões Estamparia \\
Linha 1 & 2 Vagões Shredded & $\begin{array}{c}\text { 2 Vagões } \\
\text { Tesourada }\end{array}$ & 3 Vagões Estamparia \\
\hline
\end{tabular}

Figura 12. Modelo de estoque por composição.

Com esta distribuição, o sistema calcula que seja possível realizar 19 corridas por dia, quantidade menor do que o esperado de 22 corridas, em média, para atender a meta de produção.

O sistema calcula um tempo de corrida de 76 minutos contra os 52 minutos planejados, indicando que existem gargalos importantes nos processos de carregamento.

\footnotetext{
* Contribuição técnica ao 33० Seminário de Logística - Suprimentos, PCP, Transportes, 13 a 16 de maio de 2014, São Paulo, SP, Brasil.
} 


\subsection{Determinar as Manobras Ferroviárias Necessárias ao Processo}

O sistema aponta que serão necessárias 6 manobras ferroviárias por dia para atender as 19 corridas.

\subsection{Avaliar os Recursos e Capacidades Operacionais, Levantando suas Restrições e Gargalos}

As pontes rolantes apresentaram alto nível de utilização (Figura 13), indicando que haverá desgaste acentuado dos equipamentos. Planos de manutenção preventiva devem ser aplicados para evitar paradas de produção por falha nos equipamentos.

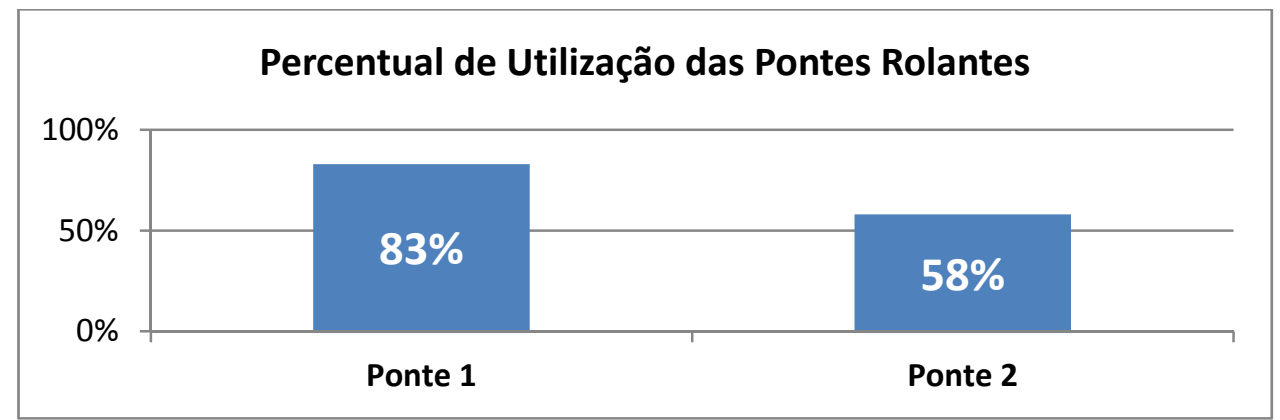

Figura 13. Nível de utilização das pontes rolantes.

O cestão 1 pode ser carregado somente pela ponte 1 por restrições de projeto o que reduz a eficiência do processo.

\section{DISCUSSÃO}

A preocupação quanto ao processo de abastecimento metálicos é válida e existem riscos significativos de que o abastecimento da nova planta de Aços Longos possa sofrer algum impacto caso medidas preventivas não sejam adotas. Foi justificada a utilização da Simulação em Computador para analisar as restrições operacionais e testar novos cenários, já que evidenciou os possíveis problemas futuros.

A análise conjunta com a equipe de produção aponta os seguintes pontos de atenção que precisam ser trabalhados para garantir que o abastecimento de metálicos não cause restrições a produção de Aço:

- Estudar alternativa de "Grab" que transporte volumes maiores do que o eletroímã, buscando aumento de eficiência na movimentação das pontes rolantes;

- Realizar manutenção preventiva efetiva nas pontes rolantes para garantir sua disponibilidade operacional, evitando paradas de produção por problemas de abastecimento de insumos;

- Avaliar o mix de sucata disponível e os impactos que possam causar aos processos de abastecimento.

O modelo mostrou que com os dados iniciais de projeto existem restrições que devem ser vencidas para não haver impactos no processo de abastecimento da aciaria. Os pontos de atenção devem ser avaliados e assim que novos dados estiverem disponíveis é importante retornar ao modelo e simular novamente as operações para garantir sua operabilidade e produtividade total dos equipamentos.

\footnotetext{
* Contribuição técnica ao 33० Seminário de Logística - Suprimentos, PCP, Transportes, 13 a 16 de maio de 2014, São Paulo, SP, Brasil.
} 


\section{REFERÊNCIAS}

1 Instituto Aço Brasil. O Aço - Processo Siderúrgico. 2014 [acesso 31 mar. 2014]. Disponível em: http://www.acobrasil.org.br/site/portugues/aco/processo--introducao.asp.

2 Chwif LM, Afonso C. Modelagem e Simulação de Eventos Discretos: teoria e aplicações. São Paulo: Ed. Bravarte; 2007. 